\title{
Modelling the cloud condensation nucleus activity of organic acids on the basis of surface tension and osmolality measurements
}

\author{
Z. Varga ${ }^{1}$, G. Kiss ${ }^{2}$, and H.-C. Hansson ${ }^{3}$ \\ ${ }^{1}$ Department of Earth and Environmental Sciences at University of Pannonia, Egyetem u. 10, 8200 Veszprém, Hungary \\ ${ }^{2}$ Air Chemistry Group of the Hungarian Academy of Sciences, University of Pannonia, P.O.Box 158, 8201 Veszprém, \\ Hungary \\ ${ }^{3}$ Institute of Applied Environmental Research, Stockholm University, Stockholm, 10691, Sweden
}

Received: 8 March 2007 - Published in Atmos. Chem. Phys. Discuss.: 19 April 2007

Revised: 15 August 2007 - Accepted: 3 September 2007 - Published: 7 September 2007

\begin{abstract}
In this study vapour pressure osmometry was used to determine water activity in the solutions of organic acids. The surface tension of the solutions was also monitored in parallel and then Köhler curves were calculated for nine organic acids (oxalic, malonic, succinic, glutaric, adipic, maleic, malic, citric and cis-pinonic). Surface tension depression is negligible for most of the organic acids in dilute $(\leq 1 \mathrm{w} / \mathrm{w} \%)$ solutions. Therefore, these compounds affect equilibrium vapour pressure only in the beginning phase of droplet formation when the droplet solution is more concentrated but not necessarily at the critical size. An exception is cis-pinonic acid which remarkably depress surface tension also in dilute $(0.1 \mathrm{w} / \mathrm{w} \%)$ solution and hence at the critical point. The surface tension of organic acid solutions is influenced by the solubility of the compound, the length of the carbon chain and also by the polar functional groups present in the molecule. Similarly to surface tension solubility plays an important role also in water activity: compounds with higher solubility (e.g. malonic, maleic and glutaric acid) reduce water activity significantly in the early phase of droplet formation while less soluble acids (e.g. succinic and adipic acid) are saturated in small droplets and the solution starts diluting only in bigger droplets. As a consequence, compounds with lower solubility have a minor effect on water activity in the early phase of droplet formation. To deduce the total effect Köhler curves were calculated and critical supersaturations $\left(\mathrm{S}_{c}\right)$ were determined for the organic acids using measured surface tension and water activity. It was found that critical supersaturation grew with growing carbon number. Oxalic acid had the lowest critical supersaturation in the size range studied and it was comparable to the activation of ammonium sulphate. The $S_{c}$ values obtained in this study were compared to data from CCNC experiments. In most
\end{abstract}

Correspondence to: G. Kiss

(kissgy@almos.uni-pannon.hu) cases good agreement was found. For modelling purposes $S_{c}$ vs. $d_{d r y}$ plots are given and the dependence of water activity and surface tension on concentration are also formulated.

\section{Introduction}

The role of organic compounds in cloud formation (and thereby in indirect aerosol forcing) has received particular attention in the past few years. It has been shown that in addition to inorganic salts organic aerosol particles can also act as cloud condensation nuclei. Köhler theory is often used to calculate the critical supersaturation corresponding to an aerosol particle of known dry size and composition. However, the reliability of the calculation strongly depends on the input parameters of the model, namely the surface tension and the water activity of the solution formed on the aerosol particle. Inorganic salts of atmospheric relevance do not change the surface tension of water significantly, so in the model calculations the surface tension of water can be used. This is not the case for organic aerosol components, some of which are surfactants, e.g. humic-like substances or other organic acids. In the past few years surface tension of cloud water (Hitzenberger et al., 2002; Decesari et al., 2004), fog water and aerosol extract (Seidl and Hänel, 1983; Capel, 1990; Facchini et al., 2000; Decesari et al., 2004; Kiss et al., 2005) as well as that of solution of individual organic compounds (Ervens at al., 2004; Shulman et al., 1996; Tuckerman and Cammenga, 2004) were studied leading to a basic knowledge on their surface tension effect. However, hardly any information is available on the water activity of such atmospheric samples or model solutions of organic compounds. Consequently, the critical supersaturation of particles consisting of a pure organic compound or mixture of different components can be estimated only with high uncertainty.

Published by Copernicus Publications on behalf of the European Geosciences Union. 
Köhler theory (Köhler, 1936) predicts the supersaturation (S) of water vapour over a solution droplet of a given radius (r):

$S=p / p_{0}-1=a_{w} \exp \left(2 \sigma M_{w} /(r \rho R T)-1\right.$

Where $\mathrm{p}$ is the water vapour pressure over the droplet solution, $p_{0}$ is the water vapour pressure over a flat water surface, $a_{w}$ is the water activity in the droplet solution, $\sigma$ is the surface tension of the droplet solution, $M_{w}$ is the molecular weight of water, $\rho$ is the density of water, $R$ is the universal gas constant and $T$ is the temperature. The vapour pressure is decreased by the dissolved matter (Raoult effect, represented by $a_{w}$ ) while the curvature of the droplet exerts an opposite effect (Kelvin effect, accounted for by the exponential term which is dependent on the surface tension of the solution.)

Water activity data for organic compounds are rare, especially for mixtures. So, often the simplified form of the Köhler equation is used to calculate the critical supersaturation:

$S=A / r-B / r^{3}$

In this equation $A / r$ represents the Kelvin effect, where $A=2 \sigma M_{w} / \rho R T$. The second term stands for the Raoult effect and $B=3 i * m_{s} / M_{s} * M_{w} / 4 \pi \rho$, where $m_{s}$ is the mass of the solute in the droplet, $M_{S}$ is the molecular weight of the solute in the droplet, $i$ is the van't Hoff factor of the solute in the droplet. It can be shown that $\mathrm{i} \sim \nu \Phi$ (Kreidenweis et al., 2005) where $v$ is the number of ions produced from one solute molecule and $\Phi$ is the molal osmotic coefficient of the solute in solution. Often $\Phi=1$ is assumed and i is considered to reflect the dissociation ability of the solute. Thus, the van't Hoff factor is about 1 for non-electrolytes and typically higher than 1 for electrolytes. This form of the Köhler equation contains several mathematical and physicochemical simplifications, which can lead to uncertainty, especially in the early phase of droplet formation when the concentration of the solute is high. The van't Hoff factor is a critical parameter in the Raoult term since it depends on the concentration of the organic compound. Furthermore, in case of mixtures other organic and inorganic species present in the solution can also influence it. Due to the lack of information on concentration dependence, fixed value of van't Hoff factor is applied in most investigations to calculate the critical supersaturation. Since organic acids are weak electrolytes, van't Hoff factor of unity is often used (Hori et al., 1996; Cruz and Pandis, 1997, 1998; Corrigan and Novakov, 1999; Prenni et al., 2001; Giebl et al., 2002; Raymond and Pandis, 2002; Kumar et al., 2003; Bilde and Svenningsson, 2004). Schulman et al. (1996) used 2 as van't Hoff factor for cis-pinonic acid while Mircea et al. (2002) applied $i=3$ for dicarboxylic acids assuming complete dissociation. In order to take into account the concentration dependence of the van't Hoff factor Kumar et al. (2003) used values between 1.2 and 2 for oxalic acid. These van't Hoff factors were de- rived from the dissociation constants and the actual concentration of oxalic acid in the droplet. Thus, reasonably good agreement between theoretical calculations and experimental results were found. While this approach gives more realistic results for strong acids than a fixed van't Hoff factor, it cannot be used for mixtures of unknown compounds (e.g. atmospheric samples) since the dissociation constants, the molecular weight and the concentration of the aerosol constituents are not known. In such a case, of course, also the fixed van't Hoff factor approach leads to high uncertainty.

In this paper we applied a new approach for the calculation of the Köhler curves. The osmolality and surface tension of a series of solution were measured then water activity was derived from osmolality. Finally, the original form of the Köhler equation (Eq. 1) was used to calculate critical supersaturation. Thus, uncertainties originating from the use of the simplified equation (Eq. 2) were eliminated. The applicability of the method was demonstrated on organic acids, since these compounds are usually found in highest concentration in aerosol samples as individual compounds. Furthermore, model calculations and measurements with cloud condensation nucleus counters (CCNC) are available for organic acids, so the results of our model calculations can be compared to these data.

\section{Experimental}

In this study nine organic acids were included: oxalic, malonic, succinic, glutaric, adipic acid (C2-C6 $\alpha, \omega$-dicarboxylic acids), maleic acid (unsaturated $\mathrm{C} 4$ dicarboxylic acid), malic acid (hydroxy $\mathrm{C} 4$ dicarboxylic acid), citric acid (hydroxy C6 tricarboxylic acid) and pinonic acid (monocarboxylic $\mathrm{C} 10$ acid, oxidation product of terpene). Basic properties of the investigated acids are summarized in Table 1. First, a solution corresponding to a defined growth factor (GF) was prepared. Then the osmolality was measured with a KNAUER K -7000 vapour pressure osmometer (VPO) at $40^{\circ} \mathrm{C}$ with equilibrium time of $3.5 \mathrm{~min}$. The working principle of the VPO is the measurement of temperature difference arising from the vapour pressure difference between a solution droplet and a pure water droplet. The advantage of the method is that the osmometer accounts for all phenomena (e.g. dissociation of electrolytes, electrostatic interactions in the solution, etc.) that influence the vapour pressure of the solution. Furthermore, the wide working range $(0.005-10 \mathrm{~mol} / \mathrm{kg}$ water) of the instrument allows activity measurement in the $0.85-1$ activity range where the electrodynamic balance is less applicable. Water activity of the organic acid solutions was derived from osmolality as suggested earlier (Kiss and Hansson, 2004; Rosenorn et al., 2005) and is given in Tables 3a-b. It is important to note that the accuracy of the measurement is very good: an error of $5 \%$ in osmolality results in an error of only $0.005-0.05 \%$ in water activity in the relevant concentration range. 
Table 1. Physical properties of the studied compounds.

\begin{tabular}{|c|c|c|c|c|c|}
\hline $\begin{array}{l}\text { Name of the } \\
\text { compound }\end{array}$ & Structural formula of the compound & $\begin{array}{l}\mathrm{MW}^{(a)} \\
\mathrm{g} \mathrm{mol}^{-1}\end{array}$ & $\begin{array}{l}\text { Density } \\
\mathrm{g} \mathrm{cm}^{-3}\end{array}$ & $\begin{array}{l}\text { Solubility } \\
\text { mol } 1^{-1}\end{array}$ & $\begin{array}{l}\text { pK1 } \\
\text { pK2 } \\
\text { pK3 }{ }^{(a)}\end{array}$ \\
\hline Oxalic acid & $(\mathrm{COOH})_{2}$ & 90.04 & 1.900 & $0.39^{(b)}$ & $\begin{array}{l}1.23 \\
4.19\end{array}$ \\
\hline Malonic acid & $\mathrm{COOH}-\mathrm{CH} 2-\mathrm{COOH}$ & 104.06 & 1.619 & $5.19^{(b)}$ & $\begin{array}{l}2.83 \\
5.69\end{array}$ \\
\hline Succinic acid & $\mathrm{COOH}-(\mathrm{CH} 2)_{2}-\mathrm{COOH}$ & 118.1 & 1.572 & $0.25^{(b)}$ & $\begin{array}{l}4.16 \\
5.61\end{array}$ \\
\hline Glutaric acid & $\mathrm{COOH}-(\mathrm{CH} 2)_{3}-\mathrm{COOH}$ & 132.12 & 1.424 & $2.26^{(b)}$ & $\begin{array}{l}4.34 \\
5.41\end{array}$ \\
\hline Adipic acid & $\mathrm{COOH}-(\mathrm{CH} 2)_{4}-\mathrm{COOH}$ & 146.14 & 1.360 & $0.05^{(b)}$ & $\begin{array}{l}4.43 \\
4.41\end{array}$ \\
\hline Maleic acid & $\mathrm{COOH}-(\mathrm{CH})_{2}-\mathrm{COOH}$ & 116.07 & 1.590 & $6.7^{(\mathrm{c})}$ & $\begin{array}{l}1.83 \\
6.07\end{array}$ \\
\hline Malic acid & $\mathrm{HOOC}-\mathrm{CH} 2-\mathrm{CH}(\mathrm{OH})-\mathrm{COOH}$ & 134.09 & 1.609 & $2.69^{(\mathrm{d})}$ & $\begin{array}{l}3.40 \\
5.11\end{array}$ \\
\hline Citric acid & $\mathrm{HOC}(\mathrm{COOH})(\mathrm{CH} 2 \mathrm{COOH})_{2}$ & 192.12 & 1.665 & $3.08^{(\mathrm{e})}$ & $\begin{array}{l}3.14 \\
4.77 \\
6.39\end{array}$ \\
\hline $\begin{array}{l}\text { Cis-pinonic } \\
\text { acid }\end{array}$ & $\mathrm{CH} 3 \mathrm{COC} 4 \mathrm{H} 4(\mathrm{CH} 3)_{2} \mathrm{CH} 2 \mathrm{COOH}$ & 184.24 & 0.786 & $0.02^{(b)}$ & n.a. \\
\hline
\end{tabular}

(a) CRC Handbook of Chemistry and Physics

(b) Shulman et al. (1996)

(c) International Occupational Safety and Health Information Centre (CIS).

(d) Belstein Handbook of Organic Chemistry

(e) Toxicology database

An FT $\AA 25$ tensiometer was applied to determine the surface tension of the solutions on the basis of pendant drop shape analysis. From a single solution drop 40 parallel measurements were done during $10 \mathrm{~s}$ at room temperature. The volume of the droplet in both measurements was about $10 \mu \mathrm{l}$ corresponding to a curvature radius of approximately $1.2 \mathrm{~mm}$. Finally, the equilibrium supersaturation was calculated with the original Köhler equation (Eq. 1).

\section{Results}

\subsection{Surface tension effect of organic acids}

Different organic acids modify the surface tension to various extents. The effect of $\alpha, \omega$-dicarboxylic acids as a function of concentration (w/w\%) is summarized in Table 2a. Oxalic, succinic and adipic acids, which contain even number carbon atoms, have lower solubility, therefore their effect was studied in a limited concentration range. As it can be seen in Table $2 \mathrm{a}$ the surface tension at $1 \mathrm{w} / \mathrm{w} \%$ slightly decreases with growing hydrophobic chain (carbon number). This effect is much stronger at higher concentrations (30$40 \mathrm{w} / \mathrm{w} \%$ ) for the compounds containing odd number carbon atoms (malonic and glutaric acids) leading to a $10-20 \%$ decrease in surface tension. Similar effect of dicarboxylic acids was observed by Shulman et al. (1996) using the droplet volume method. For cis-pinonic acid Tuckermann and Cammenga (2004) measured similar surface tension values, for example at $0.5 \mathrm{w} / \mathrm{w} \%$ they measured $0.0577 \mathrm{Jm}^{-2}$ which almost equals our result $\left(0.0576 \mathrm{Jm}^{-2}\right)$.

It must be noted that highly surface active compounds are depleted from the bulk as they are accumulated at the surface of small droplets (Li et al., 1998; Sorjama et al., 2004). However, the organic acids studied here are slightly surface active except cis-pinonic acid. Therefore the effect of distribution between the surface and the bulk of the droplet may not be a major issue. In the case of cis-pinonic acid its low solubility makes surfactant depletion less important (Sorjama et al., 2004). On the basis of these arguments it can be concluded that surface-to-bulk distribution is probably of minor importance in our results.

The presence of a double bond (maleic acid) or a hydroxyl group (malic acid) in the $\mathrm{C} 4$ dicarboxylic acid increased the water solubility and thus enhanced the depression of surface tension in concentrated solutions as compared to the $\mathrm{C} 4 \alpha, \omega$ dicarboxylic acid (succinic acid) as shown in Table $2 b$. The 
Table 2a. Surface tension values $\left[\mathrm{J} \mathrm{m}^{-2} * 10^{3}\right]$ as a function of concentration in the solutions of dicarboxylic acids. Oxalic, succinic and adipic acid, which contain even number carbon atom, have lower solubility, that is why there are no measured values at higher concentrations.

\begin{tabular}{llllll}
\hline w/w \% & $\begin{array}{l}\text { Oxalic } \\
\text { acid }\end{array}$ & Malonic acid & $\begin{array}{l}\text { Succinic } \\
\text { acid }\end{array}$ & Glutaric acid & Adipic acid \\
\hline 0.1 & - & 71 & 71 & 70 & 71 \\
0.5 & 71 & 71 & 71 & 69 & 69 \\
1 & 71 & 71 & 70 & 69 & 68 \\
5 & 71 & 70 & - & 66 & - \\
10 & - & 68 & - & 63 & - \\
30 & - & 65 & - & 59 & - \\
40 & - & 64 & - & 58 & $\sigma=67.2 /(1+(-$ \\
Fitted & - & $\sigma=71.5-$ & - & $\sigma=70.4-$ & $0.0675^{*} \exp (-$ \\
equations & & $0.381 \mathrm{c}+0.00503 \mathrm{c}^{\wedge} 2$ & & $112 * \exp \left(-4.17 * \mathrm{c}^{\wedge}-\right.$ & $2.39 * \mathrm{c})$ \\
& & & & $0.176)$ & 0.9978688 \\
r & - & 0.9757429 & - & 0.9873910 & $0.079-$ \\
w/w\% & - & $0.093-40.62$ & - & $0.08-36.86$ & 1.087 \\
range & & & & & \\
\hline
\end{tabular}

Table 2b. The surface tensions $\left[\mathrm{J} \mathrm{m}^{-2 * 10^{3}}\right.$ ] as a function of concentration in the solutions of the other organic acids studied.

\begin{tabular}{lllll}
\hline w/w \% & Maleic acid & Malic acid & Citric acid & Cis-pinonic acid \\
\hline 0.1 & 71 & 72 & 71 & 67 \\
0.5 & 71 & 72 & 71 & 58 \\
1 & 71 & 72 & 71 & - \\
5 & 69 & 71 & 69 & - \\
10 & 67 & 70 & 68 & - \\
30 & 62 & 68 & 65 & - \\
40 & 61 & 68 & 65 & - \\
Fitted & $\sigma=71.3-$ & $\sigma=72.04-$ & $\sigma=70.1-$ & $\sigma=70.9-$ \\
equations & $58.9 * \exp (-$ & $285 * \exp (-$ & $0.339 * \mathrm{c}$ & $\left.48.4 * \mathrm{c}+43.6^{*} \mathrm{c}^{\wedge} 2\right)$ \\
& $5.08 * \mathrm{c}^{\wedge}-$ & $7.086 * \mathrm{c}^{\wedge}-$ & $\left.+0.00497 * \mathrm{c}^{\wedge} 2\right)$ & \\
& $0.292)$ & $0.143)$ & & \\
r & & & & 0.9924882 \\
w/w\% range & $0.09-40.27$ & $0.095-40.45$ & $0.082-38.88$ & $0.041-0.352$ \\
\hline
\end{tabular}

effect of functional groups can be observed in the case of citric acid, too. Citric acid is a tricarboxylic acid with 6 carbon atoms and a hydroxyl group. Due to the presence of the polar functional groups its water solubility is high but the surface tension depression is moderate only (8-9\%) even in high concentration $(30-40 \mathrm{w} / \mathrm{w} \%)$ solution. Among the organic acids studied cis-pinonic acid decreased the surface tension of the solution most efficiently (by 20\%) even in a very dilute solution $(0.5 \mathrm{w} / \mathrm{w} \%)$. This feature may have an important consequence during cloud formation as it will be discussed in the next paragraph.

The impact of surface tension depression on cloud droplet activation can be better assessed if surface tension is expressed as a function of growth factor (GF) as shown in Fig. 1. It can be observed that surface tension of the droplet solution for most of the organic acids is close to that of pure water $\left(0.072 \mathrm{Jm}^{-2}\right)$ if $\mathrm{GF} \geq 4$. In other words, the surface tension depression of these compounds may affect critical supersaturation only for particles of very small dry size $(\mathrm{d}<30 \mathrm{~nm})$ because such particles activate at $\mathrm{GF}<4$.

In contrast with the dicarboxylic acids cis-pinonic acid remarkably depress surface tension also in very dilute solutions (Table 2b, Fig. 1). As a consequence, this acid is likely to decrease the Kelvin term at the critical droplet size, too. However, the critical supersaturation and critical droplet size are jointly determined by surface tension and water activity of the solution as it is discussed in the next sections. 
Table 3a. Water activity as a function of concentration in the solutions of dicarboxylic acids. For oxalic, malonic and glutaric acid literature values are also shown.

\begin{tabular}{|c|c|c|c|c|c|}
\hline $\mathrm{w} / \mathrm{w} \%$ & Oxalic acid & Malonic acid & Succinic acid & Glutaric acid & Adipic acid \\
\hline 0.01 & 1 & 1 & 1 & 1 & 1 \\
\hline 0.1 & 0.9995 & 0.9997 & 0.9998 & 0.9998 & 0.9997 \\
\hline 0.5 & 0.9984 & 0.9989 & 0.9991 & 0.9992 & 0.9993 \\
\hline 1 & 0.9971 & 0.9979 & 0.9983 & 0.9985 & 0.9987 \\
\hline 2 & 0.9944 & 0.9960 & 0.9968 & 0.9972 & - \\
\hline \multirow[t]{3}{*}{5} & 0.9865 & 0.9900 & \multirow[t]{3}{*}{-} & 0.9931 & \multirow[t]{3}{*}{-} \\
\hline & $0.982^{\mathrm{a}}$ & $0.982^{\mathrm{c}}$ & & $0.99^{c}$ & \\
\hline & $0.99^{\mathrm{b}, \mathrm{c}}$ & $0.99^{\mathrm{b}, \mathrm{d}}$ & & $0.997^{\mathrm{b}, \mathrm{d}}$ & \\
\hline \multirow[t]{4}{*}{10} & \multirow[t]{4}{*}{-} & 0.9798 & \multirow[t]{4}{*}{-} & 0.9867 & \multirow[t]{4}{*}{-} \\
\hline & & $0.96^{\mathrm{c}}$ & & $0.99^{\mathrm{a}, \mathrm{b}, \mathrm{f}}$ & \\
\hline & & $0.975^{\mathrm{d}}$ & & $0.995^{\mathrm{d}}$ & \\
\hline & & $0.98^{\mathrm{b}, \mathrm{e}}$ & & & \\
\hline \multirow[t]{5}{*}{20} & \multirow[t]{5}{*}{-} & 0.9581 & \multirow[t]{5}{*}{-} & 0.9751 & \multirow[t]{5}{*}{-} \\
\hline & & $0.925^{\mathrm{c}}$ & & $0.96^{\mathrm{c}}$ & \\
\hline & & $0.95^{\mathrm{d}}$ & & $0.97^{\mathrm{f}}$ & \\
\hline & & $0.96^{\mathrm{a}, \mathrm{b}, \mathrm{e}}$ & & $0.98^{\mathrm{a}}$ & \\
\hline & & & & $0.982^{\mathrm{d}}$ & \\
\hline \multirow{3}{*}{$\begin{array}{l}\text { Fitted } \\
\text { equations }\end{array}$} & $\mathrm{a}_{w}=0.999-$ & $\mathrm{a}_{w}=0.999-$ & $\mathrm{a}_{w}=0.999-$ & $\mathrm{a}_{w}=0.999-$ & $\mathrm{a}_{w}=0.999-$ \\
\hline & $0.00274 * \mathrm{c}$ & $0.00193 * \mathrm{c}-$ & $0.00156^{*} \mathrm{c}-$ & $0.00139 * \mathrm{c}+$ & $0.000964 * \mathrm{c}-$ \\
\hline & $\begin{array}{l}+1.75^{*} 10- \\
5^{*} \mathrm{c}^{\wedge} 2\end{array}$ & $7.83 * 10-6 * c^{\wedge} 2$ & $1.13^{*} 10-5 * c^{\wedge} 2$ & $7.88 * 10-6 * c^{\wedge} 2$ & $1.13 * 10-4 * c^{\wedge} 2$ \\
\hline $\mathrm{r}$ & 0.9999567 & 0.9999954 & 0.9999668 & 0.99999940 & 0.9994056 \\
\hline $\begin{array}{l}\text { w/w\% } \\
\text { range }\end{array}$ & $0.01-6.4$ & $0.01-18.5$ & $0.01-2.44$ & $0.01-17.15$ & $0.01-1.09$ \\
\hline
\end{tabular}

a Clegg and Seinfeld (2005, Thermodynamic model calculation)

b Peng et al. (2001, Electrodynamic Balance)

c Koehler at al. (2006, HTDMA)

d Wise et al. (2003, water activity derived from vapour pressure measurements)

e Hansen and Beyer (2004, freezing point depression)

${ }^{\mathrm{f}}$ Gaman et al. (2004, fitting earlier experimental data to the van Laar equation)

Water activity values were graphically determined from the figures in the above papers.

\subsection{Water activity of organic acid solutions}

Water activity of the organic acid solutions as a function of concentration is given in Tables $3 \mathrm{a}-\mathrm{b}$. For the sake of comparability activity values corresponding to the same concentration are shown in Tables $3 \mathrm{a}-\mathrm{b}$ but quadratic functions fitted on the data are also given for modelling purposes. Similarly to surface tension the effect of organic acids on water activity varies from compound to compound. At a given $\mathrm{w} / \mathrm{w} \%$ this difference is caused by two features primarily: molecular weight (MW) and dissociation constant (pK) of the organic acid. Compounds with lower MW and lower pK (stronger acids) produce more ions from a given mass and, consequently, decrease water activity to higher extent. If water activity is expressed as a function of GF (Fig. 2), the density of the acid has some influence, too. A compound of higher density includes more mass in a given volume, therefore results in lower water activity (assuming identical
MW and pK.) For example, oxalic acid (MW=90.04 g/mol, $\mathrm{pK}_{1}=1.23, \mathrm{pK}_{2}=4.19, \rho=1900 \mathrm{~kg} / \mathrm{m}^{3}$ ) decrease water activity to 0.983 at $\mathrm{GF}=3$ while water activity in a glutaric acid $\left(\mathrm{MW}=132.12 \mathrm{~g} / \mathrm{mol}, \mathrm{pK}_{1}=4.34, \mathrm{pK}_{2}=5.41, \rho=1400 \mathrm{~kg} / \mathrm{m}^{3}\right.$ ) droplet of the same size is as high as 0.993 . Similarly to surface tension, solubility plays an important role also in water activity: compounds with higher solubility (e.g. malonic, maleic and glutaric acid) reduce water activity significantly in the early phase of droplet formation $(\mathrm{GF}=2)$ while less soluble acids (e.g. succinic and adipic acid) are saturated below $\mathrm{GF}=4$, so these acids have constant water activity in this droplet size range and the solution starts diluting only in bigger droplets. As a consequence, compounds with lower solubility have a minor effect on water activity in the early phase of droplet formation.

Water activity has been derived in some studies for malonic, oxalic and glutaric acids from experiments with 
Table 3b. Water activity as a function of concentration in the solutions of the other organic acids studied.

\begin{tabular}{lllll}
\hline w/w\% & Maleic acid & Malic acid & Citric acid & $\begin{array}{l}\text { Cis-pinonic } \\
\text { acid }\end{array}$ \\
\hline 0.01 & 1 & 1 & 1 & 1 \\
0.1 & 0.9997 & 0.9998 & 0.9999 & 0.9998 \\
0.5 & 0.9988 & 0.9992 & 0.9994 & 0.9993 \\
1 & 0.9976 & 0.9985 & 0.9988 & 0.9990 \\
2 & 0.9954 & 0.9971 & 0.9977 & - \\
5 & 0.9888 & 0.9927 & 0.9947 & - \\
10 & 0.9790 & - & 0.9912 & - \\
20 & 0.9634 & - & 0.9893 & - \\
Fitted & $\mathrm{a} w=1-$ & $\mathrm{a} w=0.999-$ & $\mathrm{a} w=1-$ & $\mathrm{a} w=0.999-$ \\
equations & $0.00236 * \mathrm{c}+$ & $0.0014 * \mathrm{c}-$ & $0.00123 * \mathrm{c}+$ & 0.00131 \\
& $2.67 * 10-5 * c^{\wedge} 2$ & $0.00000904 * c^{\wedge} 2$ & $3.48 * 10-5 * c^{\wedge} 2$ & $+3.72 * 10-$ \\
& & & & $4 * c^{\wedge} 2$ \\
$\mathrm{r}$ & 0.9999411 & 0.99982 & 0.99982960 & 0.99642830 \\
w/w\% & $0.01-18.66$ & $0.01-5.84$ & $0.01-18.25$ & $0.01-0.6$ \\
range & & & & \\
\hline
\end{tabular}

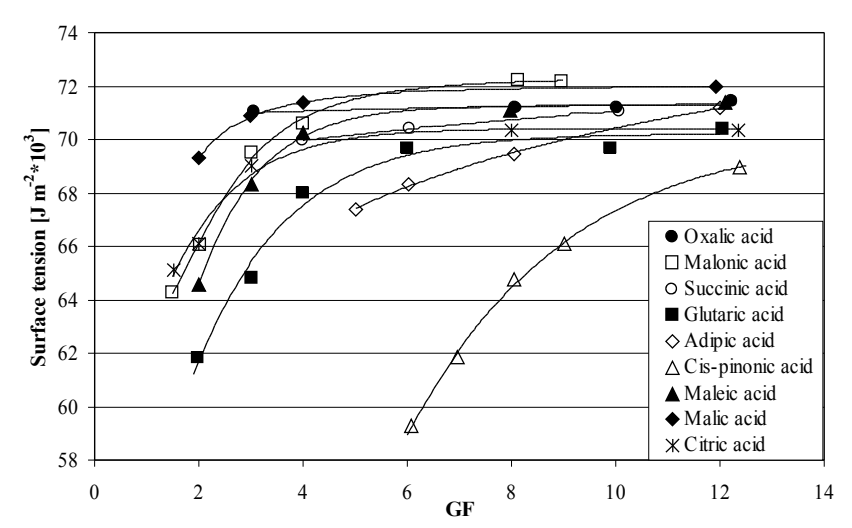

Fig. 1. Surface tension of organic acids as a function of growth factor.

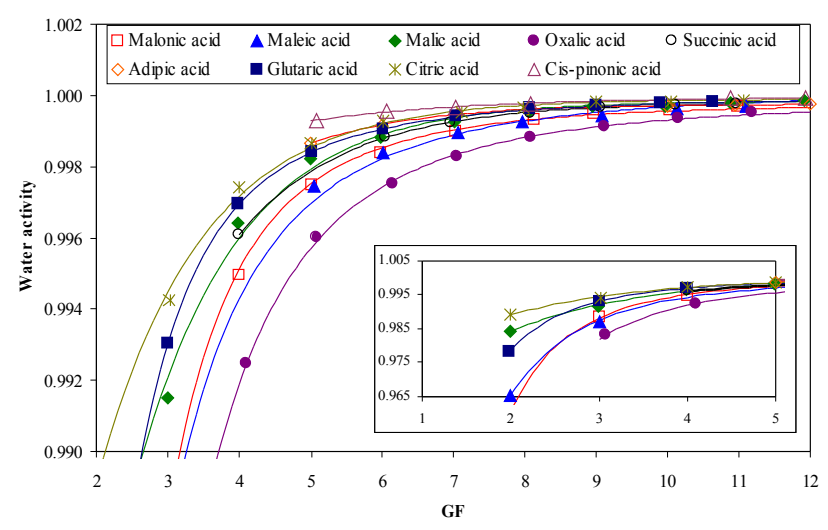

Fig. 2. Water activity of organic acids as a function of growth factor. hygroscopicity tandem differential mobility analyzer (HTDMA, Koehler et al., 2006), electrodynamic balance (EDB, Peng et al., 2001), from vapour pressure measurements (Wise et al., 2003), freezing point depression (Hansen and Beyer, 2004) thermodynamic model calculations (Clegg and Seinfeld, 2005) or by fitting earlier experimental data to the van Laar equation (Gaman et al., 2004). For oxalic acid our activity value lie in the middle of the range covered by the results by Clegg and Seinfeld (2005), Peng et al. (2001) and Koehler et al. (2006) as shown in Table 3. For malonic acid our activity values are in harmony with the activity data published by Peng et al. (2001), Wise et al. (2003), Hansen and Beyer (2004) and Clegg and Seinfeld (2005) but Koehler et al. (2006) measured somewhat lower values. For glutaric acid our results are within the range of the activity values reported by Peng et al. (2001), Wise et al. (2003), Gaman et al. (2004), Clegg and Seinfeld (2005) and Koehler et al. (2006).

As shown in Eq. (2) the simplified Köhler equation requires the van't Hoff factor $(i)$ of the solute as an input. This introduces the largest uncertainty into the Raoult term and the calculation of saturation. The maximum value of the van't Hoff factor equals 3 for dicarboxylic acids since from one molecule 2 protons and an acid anion can be formed. However, the maximum value is reached only in infinitely dilute solutions when dissociation is complete. In more concentrated solutions the value of van't Hoff factor can be significantly less and depends on the dissociation constants and the osmotic coefficient of the acid. Since the osmometer accounts for both dissociation of solute and non-ideality of solution, osmolality data can be used to calculate van't Hoff factors. Such calculation was performed with some organic acids in a growing droplet using Eq. (3) and the results are shown in Fig. 3. 


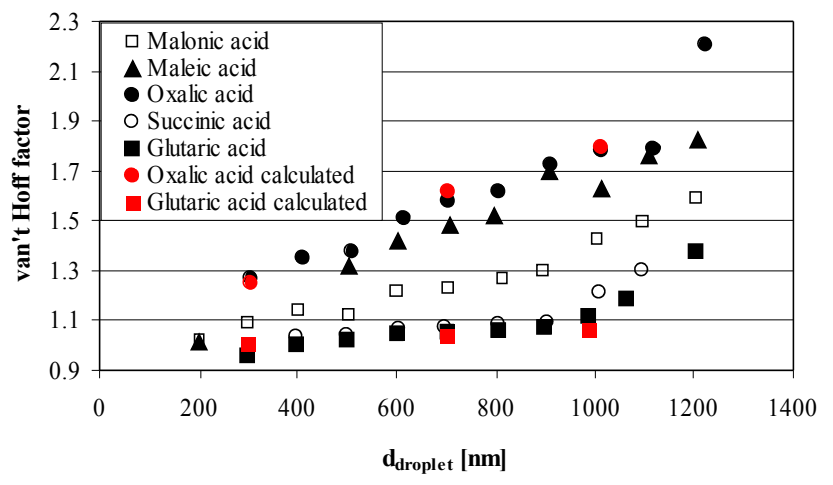

Fig. 3. Van't Hoff factors of organic acids in a droplet formed on a dry particle of $100 \mathrm{~nm}$ in diameter. The red points show the van't Hoff factors calculated from the dissociation constants of the acids.

$C_{\mathrm{osm}}=i * m$

$\begin{aligned} \mathrm{C}_{\mathrm{osm}} & =\text { osmolality } \\ \text { where } i & =\text { van't Hoff factor It can be seen that the } \\ m & =\text { molality }\end{aligned}$ van't Hoff factors grow with decreasing concentration as a consequence of increasing degree of dissociation. Furthermore, at a given concentration oxalic acid produces the most ions since it is the strongest acid among the compounds studied. In Fig. 3 van't Hoff factors for oxalic and glutaric acids calculated from dissociation constants are also shown. The agreement between these values and the osmolality-derived van't Hoff factors is good, indicating that the solutions can be considered as ideal solutions. Our results partially differ from those calculated by Sun and Ariya (2006) from water activity values reported earlier: they obtained increasing van't Hoff factor with increasing concentration for malonic acid and found higher $i$ values for succinic than oxalic acid in the $0.1-1 \mathrm{~mol} / \mathrm{kg}$ concentration range. These results are contradictory to the dissociation constants of the acids.

It can also be observed in Fig. 3 that the actual $i$ value in growing droplets and also around the critical size $\left(\mathrm{d}_{\text {droplet }}=550-870 \mathrm{~nm}\right)$ is significantly less than 3 . In Figs. 4a-b Köhler curves for oxalic and succinic acids obtained with the original Köhler equation (Eq. 1) by using real water activity and surface tension values are compared to curves calculated with the simplified Köhler equation (Eq. 2) assuming constant van't Hoff factors of 1, 2 and 3. It can be concluded that the critical supersaturation of oxalic acid can be approximated with a curve assuming constant $i$ between 1 and 2 ( $i=1.75$ exactly). For succinic acid a hypothetic constant van't Hoff factor of 1 would give a good estimate as a consequence of the weaker acidity of the acid. However, the use of $i=3$ (i.e. the assumption of full dissociation) would result in a 2-3-fold overestimation in the magnitude of the Raoult term and thus a significant $(24 \%$ and $39 \%$, respectively) underestimation of the critical supersaturation of a $\mathrm{d}_{\mathrm{dry}}=100 \mathrm{~nm}$ oxalic acid and a succinic acid particle.

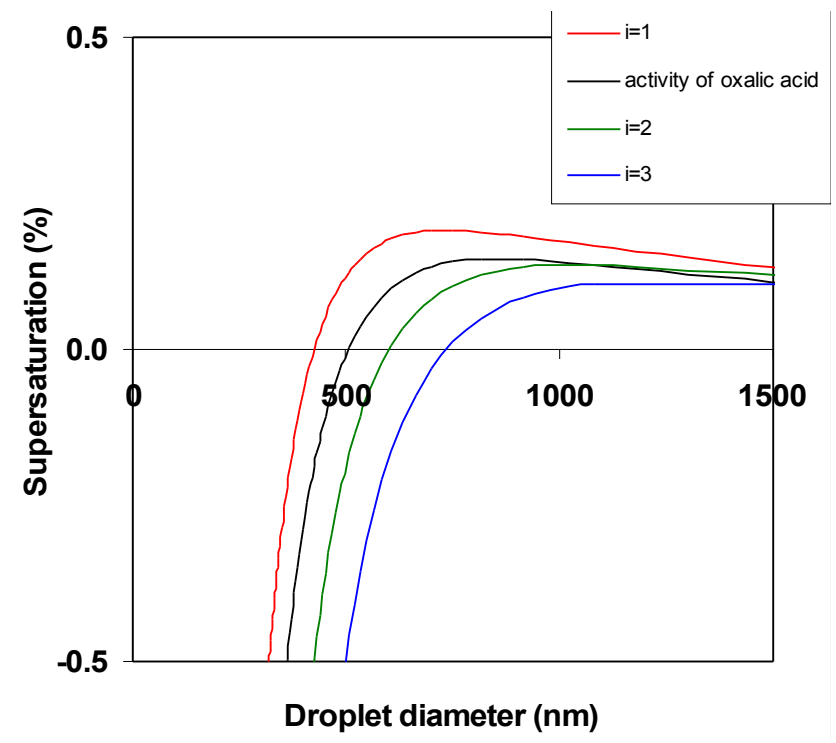

Fig. 4a. Köhler curves for oxalic acid using the original Köhler equation with measured data ("activity of oxalic acid"), and the simplified equation with different van't Hoff factors (" $i=1,2$ and 3").

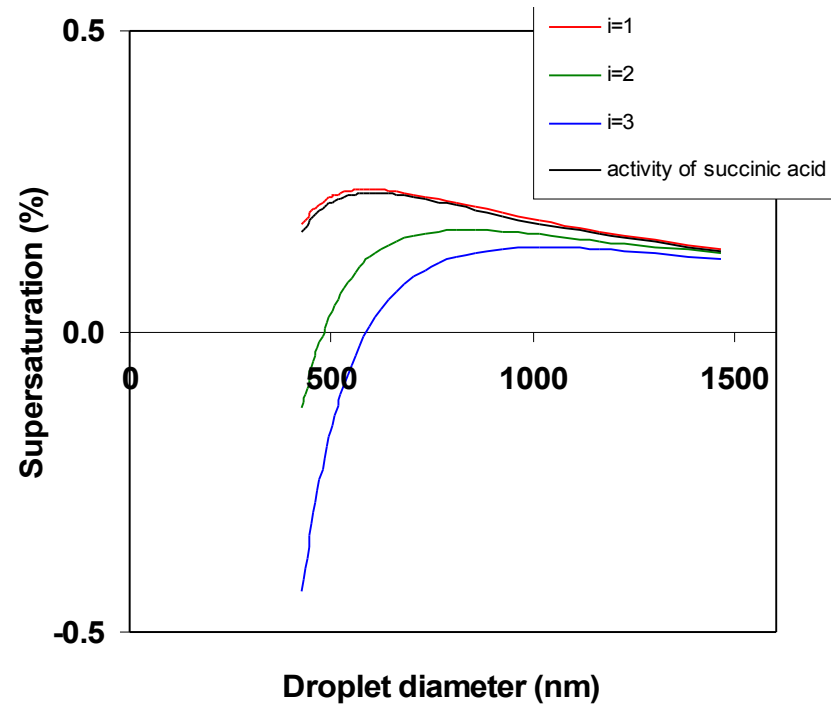

Fig. 4b. Köhler curves for succinic acid using the original Köhler equation with measured data ("activity of succinic acid"), and the simplified equation with different van't Hoff factors (" $i=1,2$ and 3").

\subsection{Critical supersaturation of organic acids}

Once the surface tension and water activity are known as a function of concentration (or GF) Köhler curves can be calculated for a dry nucleus of a given size. The maximum value of the Köhler curve gives the critical supersaturation corresponding to an organic acid particle of that dry size. 


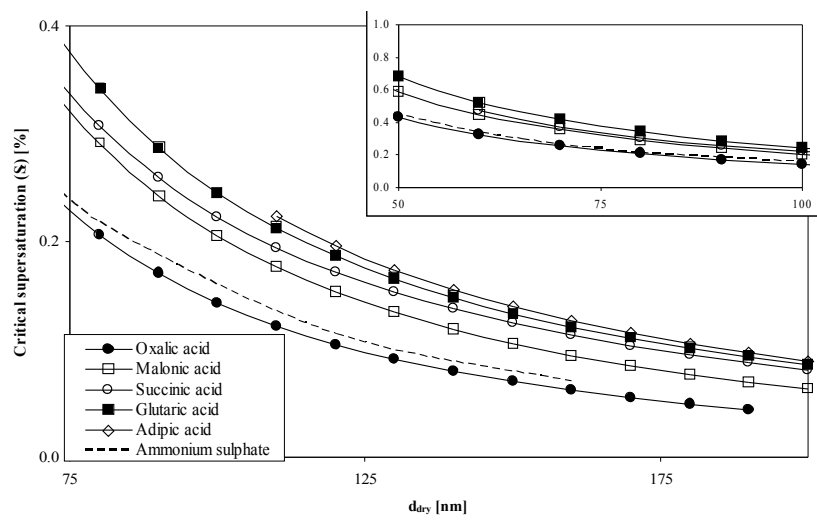

Fig. 5. Critical supersaturation as a function of dry particle diameter for the $5 \alpha, \omega$-dicarboxylic acids studied.

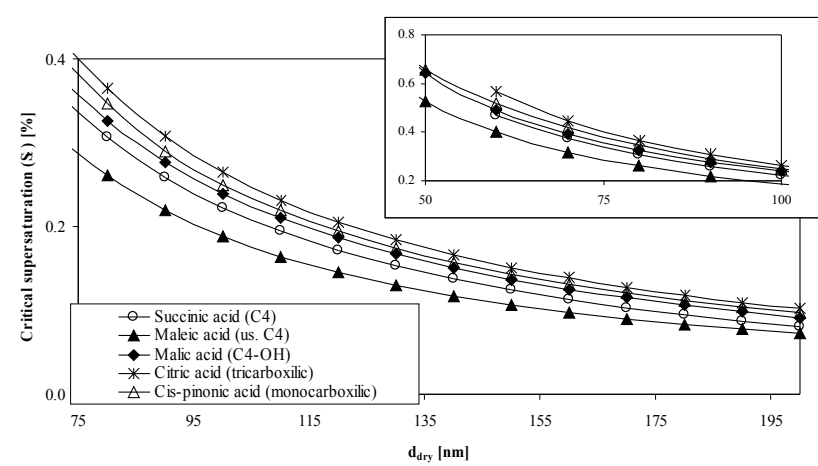

Fig. 6. Critical supersaturation as a function of dry particle diameter for the other organic acids studied.

Performing the calculation for nuclei of various sizes the critical supersaturation as a function of dry diameter can be obtained as shown for $\alpha, \omega$-dicarboxylic acids in Fig. 5. The critical supersaturation grows with growing carbon number. Oxalic acid, which contains only two carbon atoms, has the lowest critical supersaturation at any dry particle diameter. It is also visible in Fig. 5 that $S_{c}$ of oxalic acid is comparable to that of ammonium sulphate. It can also be seen in the figure that for a given compound the critical supersaturation decreases with growing dry diameter. Critical supersaturations for the other organic acids are shown in Fig. 6 . As it can be seen, the unsaturated dicarboxylic acid (maleic acid) can activate the most easily among these compounds as a consequence of its relatively strong effect on water activity (Fig. 2) and surface tension (Fig. 1). The critical supersaturations of the other acids are very similar to that of succinic acid. It is worth noting that cis-pinonic acid can activate at high supersaturation despite the fact that its surface tension lowering ability is by far the strongest among the nine acid studied (Fig. 1). This can be explained by the low water-solubility and low degree of dissociation of the acid which lead to a negligible decrease in water activity
(Fig. 2). Cis-pinonic acid and oxalic acid are good examples that Kelvin and Raoult effects have to be considered simultaneously. Evaluation of their CCN ability based on mere surface tension data would lead to significant under- and overestimation of critical supersaturation, respectively, similarly to what was concluded from the scientific discussion between Facchini et al. (2001) and Rood and Williams (2001) about the possible effect of organic aerosol constituents on critical supersaturation.

Critical supersaturations calculated from surface tension and osmolality measurements were compared to CCNC measurements. Results for dicarboxylic acids and cis-pinonic acid are shown in Fig. 7. Two curves were calculated for oxalic acid (Fig. 7a), one starting from anhydrous oxalic acid particles and the other one assuming oxalic acid dehydrate. (Results shown in previous Figures refer to anhydrous oxalic acid.) On the basis of aerosol infrared spectroscopy $\mathrm{Ku}-$ mar et al. (2003) concluded that at RH $>15 \%$ oxalic acid exists in dihydrate form. Perfect fit was observed between the CCNC data by Kumar et al. (2003) and our model calculation assuming the activation of oxalic acid dihydrate particles. However, these values differed significantly from the CCNC result by Prenni et al. (2001). Good agreement was found for malonic acid (Fig. 7b) with the CCNC measurements by Prenni et al. (2001), Giebl et al. (2002) and Kumar et al. (2003). Although Giebl et al. (2002) reported consistently lower, while Kumar et al. (2003) consistently higher dry diameters at a given supersaturation than the results of our calculation, in most cases these deviations were within the confidence interval of the experimental results. For succinic acid (Fig. 7c) we obtained slightly lower dry diameters than Corrigan and Novakov (1999) and Hartz et al. (2006), but the CCNC result of Prenni et al (2001) fitted our curve very well. It must be noted that because of the limited solubility of succinic acid our experimentally based model calculations were limited to $d_{d r y} \geq 60 \mathrm{~nm}$. Thus, the comparison with the result of $d_{\text {dry }}=46 \pm 8 \mathrm{~nm}$ by Hartz et al. (2006) is somewhat arbitrary. For glutaric acid (Fig. 7d) our results agreed well with the CCNC results by Raymond and Pandis (2002) and Kumar et al. (2003) but they were significantly lower than the dry diameters published by Cruz and Pandis (1997). For adipic acid (Fig. 7e) and cis-pinonic acid (Fig. 7f) the comparison did not show good agreement. The water solubility of these acids was the lowest among the organic compounds studied. As concluded by Bilde and Svenningsson (2004) slightly soluble compounds have two local maxima in their activation curve: the first one being the higher and the second (lower) one corresponding to traditional Köhler theory. Since our curves were calculated by using the traditional Köhler theory (Eq. 1), the discrepancy between our results and CCNC data is understandable. It must be noted, however, that the uncertainty of CCNC measurements is also high for these compounds, e.g. the dry diameter corresponding to $1 \%$ supersaturation spans from $52 \mathrm{~nm}$ (Cruz and Pandis, 1997) to $170 \pm 29 \mathrm{~nm}$ (Hartz et al., 2006). 

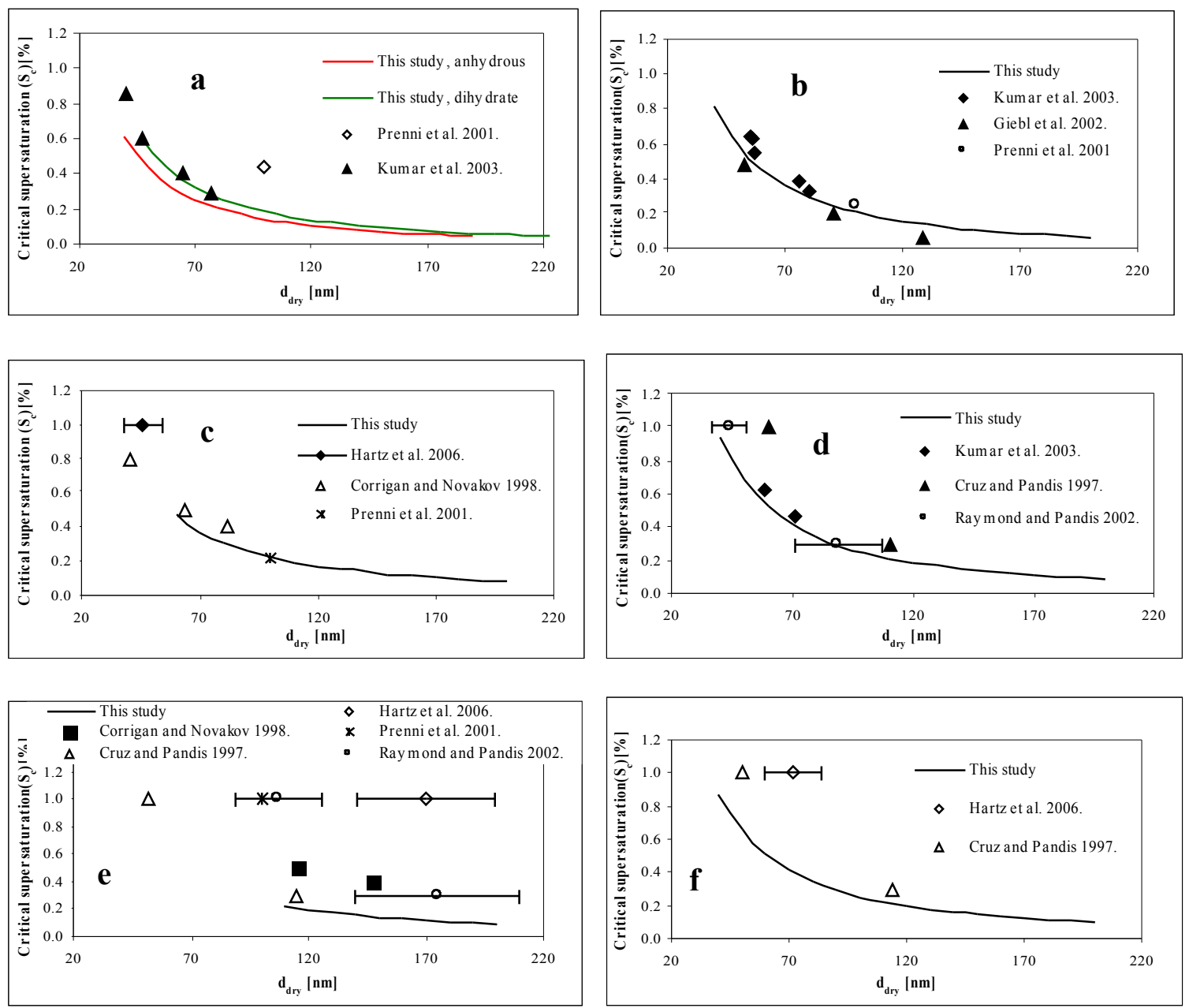

Fig. 7. Comparison of our results with CCNC data for (a) oxalic, (b) malonic, (c) succinic (bar means the confidence interval of the results by Hartz et al., 2006), (d) glutaric (bar means the confidence interval of the results by Raymond and Pandis, 2002), (e) adipic (bar means the confidence interval of the results by Hartz et al., 2006 and Raymond and Pandis, 2002) and (f) cis-pinonic acid (bar means the confidence interval of the results by Hartz et al., 2006).

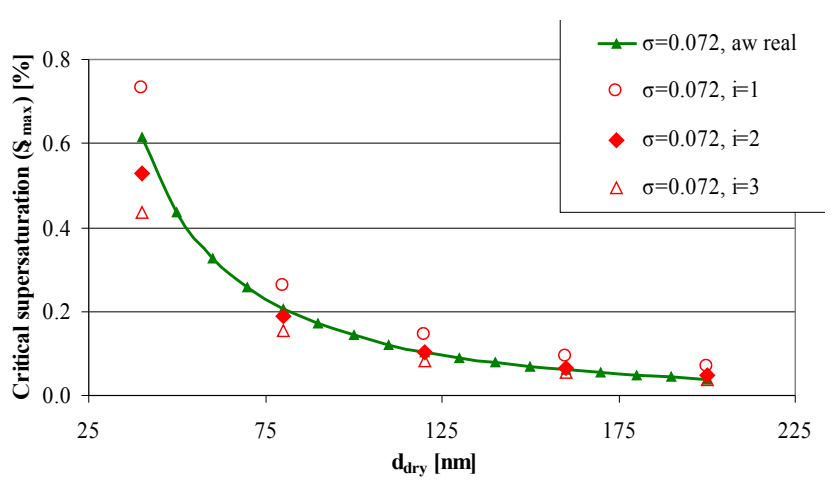

Fig. 8a. Calculated critical supersaturations for oxalic acid as a function of dry diameter using water activity data or assuming constant van't Hoff factors of 1,2 or 3 .

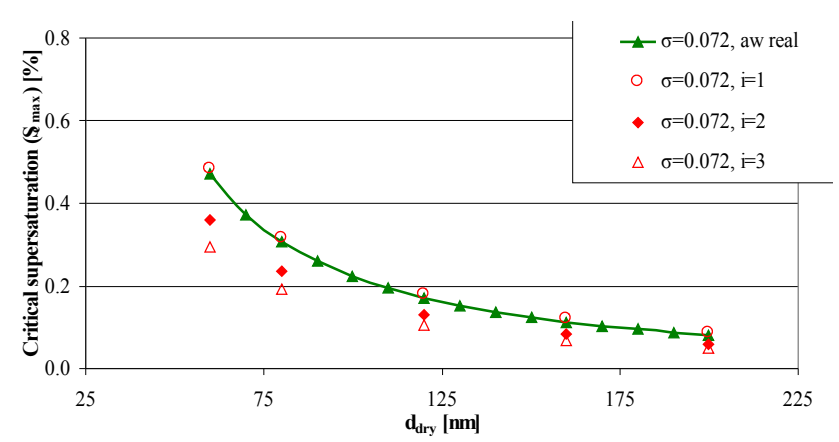

Fig. 8b. Calculated critical supersaturations for succinic acid as a function of dry diameter using water activity data or assuming constant van't Hoff factors of 1,2 or 3 . 
Actually, the difference between our results and CCNC data is not bigger than the difference between CCNC data of various groups.

Finally, we compared the calculated supersaturations obtained by using real surface tension and water activity with supersaturations estimated by applying different simplifications:

1. Instead of the surface tension of the organic acid solution the surface tension of water $\left(0.072 \mathrm{~J} \mathrm{~m}^{-2}\right)$ was used.

2. Instead of water activity the Raoult effect was estimated by Eq. (2) assuming $i=1,2$ or 3 .

Such curves are shown for oxalic and succinic acid on Figs. $8 \mathrm{a}$ and $\mathrm{b}$, respectively. The curves calculated with real water activity and with or without simplification A were identical for both acids as a consequence of their negligible surface tension lowering effect. However, simplification $B$ made a substantial difference: for oxalic acid the curve obtained with $\sigma=0.072 \mathrm{Jm}^{-2}$ and $i=2$ gave the best estimate, especially with increasing $d_{d r y}$. For smaller particles $\left(\mathrm{d}_{\mathrm{dry}}<100 \mathrm{~nm}\right)$ this simplification resulted in the underestimation of the critical supersaturation because the concentration of the solution at the critical point is higher for smaller particles and therefore the dissociation of oxalic acid is suppressed, yielding $\mathrm{i}<2$. For succinic acid the situation is somewhat different, the simplification of $0.072 \mathrm{Jm}^{-2}$ and $\mathrm{i}=1$ gave good approximation throughout the size range studied $\left(60<\mathrm{d}_{\mathrm{dry}}<200 \mathrm{~nm}\right)$. This can be explained with the lower degree of dissociation of succinic acid.

\section{Conclusions}

In this study solution of nine organic acids were investigated with a tensiometer and a vapour pressure osmometer to calculate their activation with the original form of the Köhler equation. Some acids with good water solubility decreased the surface tension considerably in the beginning phase of the droplet formation when the droplet solution is rather concentrated. However, the surface tension depression was negligible at low concentration corresponding to the conditions present in the droplet at activation. The only exception was cis-pinonic acid, which decreased the surface tension to $0.0576 \mathrm{Jm}^{-2}$ even in dilute solution $(0.5 \mathrm{w} / \mathrm{w} \%)$. The presence of a double bond (maleic acid) or a hydroxyl group (malic acid) in the $\mathrm{C} 4$ dicarboxylic acid increased the water solubility and thus enhanced the depression of surface tension in concentrated solutions as compared to the $\mathrm{C} 4 \alpha \omega$ dicarboxylic acid (succinic acid). However, the dominance of polar functional groups in citric acid led to a moderate surface tension depression only even in high concentration $(30-40 \mathrm{w} / \mathrm{w} \%)$ solutions. Water activity of the organic acid solutions was found to be primarily determined by the dissociation constant and molecular weight of the compounds: well dissociating small acids decreased water activity most efficiently. As a consequence, oxalic acid solutions had the lowest water activity at a given concentration. It was found that among the organic acids studied oxalic acid particles activated at the lowest supersaturation despite the negligible effect on surface tension. Its $\mathrm{CCN}$ ability was found to be close to that of ammonium sulfate. On the other hand, cis-pinonic acid activated at high supersaturation despite the fact that its surface tension lowering ability was by far the strongest among the nine acids studied. These examples clearly show that Kelvin and Raoult terms together define whether an organic compound promote or hinder activation.

Results of our model calculations were compared to data obtained in CCNC experiments and good agreement was found when consistent CCNC data were available. This confirms that our method, which is based on the measurement of surface tension and osmolality, can be used for the description of the activation of organic acids. Furthermore, the method is very useful for organic mixtures, organic-inorganic mixtures and real aerosol samples when the estimation of the van't Hoff factor is more difficult or impossible, and thus osmolality-derived water activity decreases the uncertainty of the calculations substantially. The demonstration of the method on such mixtures and real aerosol samples is the subject of further studies.

Acknowledgements. The authors are grateful to Knauer $\mathrm{GmbH}$ (Germany) for lending an osmometer for this study. The supports of the NKFP 3A089/2004 project and the János Bolyai Research Fellowship of the Hungarian Academy of Sciences are also gratefully acknowledged.

Edited by: T. Koop

\section{References}

Bilde, M. and Svenningsson, B.: CCN activation of slightly soluble organics: the importance of small amounts of inorganic salt and particle phase, Tellus Ser. B-Chem. Phys. Meteorol., 56(2), 128 134, 2004

Capel, P. D., Gunde, R., Zurcher, F., and Giger, W.:Carbon speciation and surface tension of fog, Environ. Sci. Technol., 24 722-727, 1990.

Corrigan, C. E. and Novakov T.: Cloud condensation nucleus activity of organic compounds: a laboratory study, Atmos. Environ. 33, 2661-2668, 1999.

Cruz, C. N. and Pandis, S. N.: A study of the ability of pure secondary organic aerosol to act as cloud condensation nuclei, Atmos. Environ., 31(15), 2205-2214, 1997

Cruz, C. N. and Pandis, S. N.: The effect of organic coatings on the cloud condensation nuclei activation of inorganic atmospheric aerosol, J. Geophys. Res., 103(D11), 13 111-13 123, 1998.

Decesari, S., Facchini, M. C., Fuzzi, S., Mcfiggans, G. B., Coe, H., and Bower, K. N.: The water-soluble organic component of sizesegregated aerosol, cloud water and wet deposition from Jeju island during ACE-Asia, Atmos. Environ., 39, 211-222, 2005. 
Ervens, B., Feingold, G., Clegg, S. L., and Kreidenweis, S. M.: A modelling study of aqueous production of dicarboxylic acids: 2. Implication for cloud microphysics, J. Geophys. Res., 109, D15206, doi:10.1029/2003JD004387, 2004.

Facchini, M. C., Decesari, S., Mircea, M., Fuzzi, S., and Loglio, G.: Surface tension of atmospheric wet aerosol and cloud/fog droplets in relation to their organic carbon content and chemical composition, Atmos. Environ., 34(28), 4853-4857, 2000.

Gaman, A. I., Kulmala, M., Vehkamaki, H., Napari, I., Mircea, M., Facchini, M. C., and Laaksonen, A.: Binary homogeneous nucleation in water-succinic acid and water-glutaric acid system, J. Chem. Phys., 120(1), 282-291, 2004.

Giebl, H., Berner, A. , Reischl, G., Puxbaum, H., Kasper-Giebl, A., and Hitzenberger, R.: CCN activation of oxalic and malonic acid test aerosols with the University of Vienna cloud condensation nuclei counter, Journal of Aerosol Science, 33, 1623-1634, 2002.

Hansen, A. R. and Beyer, K. D.: Experimentally determined thermodinamical properties of the malonic acid/water system: Implication for atmospheric aerosols, J. Phys. Chem. A., 108(16), 3457-3466, 2004.

Hartz, K. E. H., Tischuk, J. E., Chan, M. N., Chan, C. K., Donahue, N. M., and Pandis, S. N.: Cloud condensation nuclei activation of limited solubility organic aerosol, Atmos. Environ., 40, 605617, 2006.

Hitzenberger, R., Berner, A., Kasper-Giebl, A., Loflund, M., and Puxbaum, H.: Surface tension of Rax cloud water and its relation to the concentration of organic material, J. Geophys. Res., 107(D24), 4752, doi:10.1029/2002JD002506, 2002.

Hori, M., Ohta, S., Murao, N., and Yamagata, S.: Activation capability of water soluble organic substances as CCN, Aerosol Sci., 34, 419-448, 2003.

Kiss, G. and Hansson, H.-C.: Application of osmolality for the determination of water activity and the modelling of cloud formation, Atmos. Chem. Phys. Discuss., 4, 1-23, 2004, http://www.atmos-chem-phys-discuss.net/4/1/2004/.

Kiss, G., Tombácz, E., and Hansson, H.-C.: Surface tension effects of humic-like substances in aqueous extract of tropospheric fine aerosol, J. Atmos. Chem., 50, 279-294, 2005.

Koehler, K. A., Kreidenweis, S. M., DeMott, P. J, Prenni, A. J., Carrico, C. M., Ervens, B., and Feingold, G.: Water activity and activation diameters from hygroscopicity data-Part II.: Application to organic species, Atmos. Chem. Phys., 6, 795-809, 2006, http://www.atmos-chem-phys.net/6/795/2006/.

Kumar, P. P., Broekhuizen, K., and Abbat, J. P. D.: Organic acid as cloud condensation nuclei: laboratory study of soluble and insoluble species, Atmos. Chem. Phys., 3, 509-520, 2003, http://www.atmos-chem-phys.net/3/509/2003/.
Li, Z., Williams, A. L., and Rood, M. J.: Influence of soluble surfactant properties on the activation of aerosol particles containing inorganic solute, J. Atmos. Sci., 55, 1859-1866.,1998.

Mircea, M. , Facchini, M. C., Decesari, S., Fuzzi, S., and Charlson R. J.: The influence of the organic aerosol component on CCN supersaturation spectra for different aerosol types, Tellus, 54b, 74-81, 2002.

Peng, C., Chan, M. N., and Chan, C. K.: The hygroscopic properties of dicarboxylic and multifunctional acids: Measurements and UNIFAC predictions, Environ. Sci. Technol., 35(22), 449-54501, 2001.

Prenni, A. J., De Mott, P. J., Kreidenweis, S. M., Sherman D. E., Russell, L. M., and Ming, Y.: The effects of low molecular weight dicarboxylic acids on cloud formation, J. Phys. Chem. A, 105, 11240-11 248, 2001.

Raymond, T. M. and Pandis, S. N.: Cloud activation of singlecomponent organic aerosol particles, J. Geophys. Res.-Atmos., 107(D24), 4787, doi:10.1029/2002JD002159, 2002.

Robert, C. W.: Handbook of Chemistry and Physics, 55th edition, CRC Press, 1974-1975.

Rosenørn, T., Kiss G., and Bilde, M.: Cloud droplet activation of saccharides and levoglucosan particles, Atmos. Environ., 40, 1794-1802, 2006.

Rood, M. J. and Williams, A. L.: Comments on "Influence of soluble surfactant properties on the activation of aerosol particles containing inorganic solute" - Reply, J. Atmos. Sci., 58, 14681473, 2000.

Seidl, W. and Hänel, G.: Surface-active substances on rainwater and atmospheric particles, Pure Appl. Geophys. 121, 1077-1093., 1983.

Shulman, M. L., Jacobson, M. C., Carlson, R. J., Synovec, R. E., and Young, T. E.: Dissolution behaviour and surface tension effects of organic compounds in nucleating cloud droplets, Geophys. Res. Lett., 23(3), 277-280, 1996

Sorjamaa, R., Svenningsson B., Raatikainen, T., Henning, S., Bilde, M., and Laaksonen, A.: The role of surfactants in Köhler theory reconsidered, Atmos. Chem. Phys., 4, 2107-2117, 2004, http://www.atmos-chem-phys.net/4/2107/2004/.

Sun, J. and Ariya, P. A.: Atmospheric organic and bio-aerosols as cloud condensation nuclei $(\mathrm{CCN})$ : A review, Atmos. Environ., 40, 795-820, 2006.

Tuckermann, R. and Cammenga, H. K.: The surface tension of aqueous solutions of some atmospheric water-soluble organic compounds, Atmos. Environ., 38, 6135-6138, 2004.

Wise, M. E., Surrat, J. D., Curtis, D. B., Shilling, J. E., and Tolbert, M. A.: Hygroscopic growth of ammonium sulfate/dicarboxylic acid, J. Geophys. Res., 108(D20), 4638, doi:10.1029/2003JD003775, 2003. 